\title{
Rainfall Frequency Analysis of Sudan by Using Bayesian Markov chain Monte Carlo (MCMC) methods
}

\author{
Badreldin G. H. Hassan, Isameldin A. Atiem \\ Faculty of Engineering Science, Dep. of Civil Eng. \\ University of Nyala \\ Nyala, Sudan \\ badr36hassan@yahoo.com, isam eldin@hotmail.com
}

\author{
Feng Ping \\ Civil Engineering Department \\ Tianjin University \\ tianjin, china \\ fengping@tju.edu.cn
}

\begin{abstract}
This paper deals with at-site rainfall frequency estimation in the case when also information on hydrological events from the past with extraordinary magnitude is available. For the joint frequency analysis of systematic observations and historical data, respectively, the Bayesian framework is chosen, which, through adequately defined likelihood functions, allows for incorporation of different sources of hydrological information, e.g., mean annual rainfall, historical events as well as measurement errors. The distribution of the parameters of the fitted distribution function and the confidence intervals of the rain quantiles are derived by means of the Markov chain Monte Carlo simulation (MCMC) technique.

The paper presents a sensitivity analysis related to the choice of the most influential parameters of the statistical model, which are the length of the historical period $h$ and the perception threshold $X_{0}$. These are involved in the statistical model under the assumption that except for the events termed as 'historical' ones, none of the (unknown) rains from the historical period $h$ should have exceeded the threshold $X_{0}$. Both higher values of $h$ and lower values of $X_{0}$ lead to narrower confidence intervals of the estimated rain quantiles; however, it is emphasized that one should be prudent of selecting those parameters, in order to avoid making inferences with wrong assumptions on the unknown hydrological events having occurred in the past.

The Bayesian MCMC methodology is presented on the example of the mean annual rains observed at Sudan in the period 1901-2002.
\end{abstract}

Keywords-frequency analysis; Markov chain Monte Carlo simulation (MCMC); mean annual rainfall; threshold; historical data

\section{INTRODUCTION (HEADING 1)}

The hydrologic and hydrometeorological extremes and critical thresholds derived from complex hydrological and meteorological events for engineering design are usually obtained on the basis of single site characteristics (e.g., the annual maximum daily rainfall or discharge). Therefore, hydrological and meteorological frequency analyses have also mainly focused on one characteristic value (e.g., ${ }^{[9]-[4]}$. Various methods have been proposed to reduce the uncertainties of at-site rainfall frequency analyses and produce more robust rains quantile estimates based on larger sample sizes. Two main families of approaches can be distinguished ${ }^{[17]}$ : (i) 'Spatial extension' of information on rainfall through regional rainfall frequency methods based on aggregating statistically homogeneous data to build large data samples ${ }^{[13]}$, and

(ii) 'Temporal extension' of information on rainfall through at-site rainfall frequency studies on gauged streams extended by historical rainfall ${ }^{[22]}$.

To overcome the problem of relatively short data series for frequency analysis the need to investigate extremes also spatially was traditionally widely acknowledged in the hydrological community. The very basic paradigm of this approach originates from the index flood method introduced by Dalrymple ${ }^{[10]}$ and it is commonly used to implement a regional frequency analysis for a particular variable of interest. The aim of regional frequency analysis is to increase the information content of the analysis and to reduce the uncertainty of the design values estimates by 'trading space for time'. To address this issue, spatial (Regional) properties of extremes are studied and regional frequency analysis is typically applied. The regional approaches usually involve two major steps: the delineation of homogeneous regions (sometimes referred to as 'pooling groups') and the estimation of extreme value quantiles at the sites of interest using information from all sites in the region. Traditionally, homogeneous pooling groups were formed based on geographical position or administrative boundaries [19]-[3]-[29]. Therefore, Acreman and Wiltshire ${ }^{[1]}$ suggested a pooling approach with no need of having adjacent members in groups, i.e., groups defined in a flexible way.

This concept was further developed in different ways: Burn ${ }^{[5]}$ introduced the region of influence (ROI) focused pooling method, while various clustering techniques ${ }^{[5]}$ and canonical correlation analysis ${ }^{[20]}$ have been proposed to form homogeneous pooling groups. An important role among the various regional frequency analysis methods has the one based on the L-moments ${ }^{[13]}$. Numerous authors contributed to refinements of these directions of research ${ }^{[14]}$ $-[25]-[17]-[6]$.

A large part of our knowledge on extreme rainfall values is based on inventories of data regarding

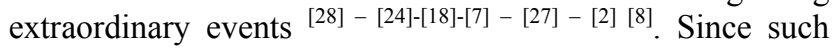
extraordinary events are important source of information on the rainfall extremes, attempts were undertaken to include these into at-site frequency analyses ${ }^{[12]-[26]-[21]}$. This is 
obtained in this section by including past historical mean annual values in rainfall frequency analyses by the Bayesian Markov chain Monte Carlo (MCMC) framework ${ }^{[15][22]}$. Let us illustrate the principles of the inclusion of historic data in at-site rainfall frequency analyses. Suppose that the information on historical hydrological consists of $\mathrm{m}$ extraordinary rainfall events, and the joint data sample of systematic and historical observations is stationary. In order to properly account for the historical information, the evaluation of the $\mathrm{m}$ historical mean annual rainfall is not sufficient. It is also important to consider the number of years $h$ in which these events were the major rains and to evaluate the threshold $\mathrm{X}_{0}$ which has certainly not been exceeded during this period by the other rains. In other words, the historical information consists not only in the $\mathrm{m}$ mean annual values but also in $h-m$ years of nonexceedance of the threshold $\mathrm{X}_{0}$. The choice of $\mathrm{h}$ and $\mathrm{X}_{0}$ should meet the criterion of "exhaustiveness" (i.e., no other major rains should have exceeded $\mathrm{X}_{0}$ in the period of time $\mathrm{h})$, which is a necessary condition for a proper statistical inference with censored data ${ }^{[16]-[11]}$. The Bayesian MCMC procedure ${ }^{[22]}$ is a flexible tool, which can handle the information both on the historical and systematic observations through adequately defined likelihood functions in a straightforward way, and more importantly, can account for uncertainties in the measurements of the hydrologic extremes, and provides estimates of confidence bounds for the estimated quantiles. It has been demonstrated that the inclusion of the historic period leads to a clear reduction of the confidence intervals ${ }^{[22]}$.

This section aims at demonstrating that this method, although it may bring a significant added value in rainfall frequency analyses, is still not free from subjectiveness and both skill and care have to be exercised when applied. Several choices that have to be made are not trivial.

\section{THE DATA}

The data used have been collected from 15 rain gauging stations, the records of which are published by the Sudan National Meteorology Department. Altitude and latitude have been assumed as initial statistics of hydrologic homogeneity, and station selection criteria were based on these characteristics. All sites used in this procedure are located between $31^{\circ} 50$ and $33^{\circ} 25 \mathrm{~N}$ latitudes, and 1530 and $2300 \mathrm{~m}$ altitudes (MSL). Records used for the analysis have ended the same year, and there are no gaps in the records (Table I).

\section{METHODOLOGY}

Bayesian Markov chain Monte Carlo (MCMC) methods provide a computationally convenient way to fit frequency distributions for rainfall frequency analysis by using different sources of information as large rainfall records, historical rains, uncertainties (particularly measurement errors), regional information and other hydrologic information. They also provide an attractive and straightforward way to estimate the uncertainty in parameters and quantile metrics ${ }^{[23]}$.

Since a rainfall frequency analysis with information on historical events included is a relatively complex methodology, in the next subsections the most relevant details and settings of the procedure.

\section{A. Selecting Bayesian inference}

The Bayesian approach is a branch of statistical analysis that is based on a unique philosophy: the statistical inference is drawn in the way that the initial beliefs on the subject of the interest are modified according to the observed data. Thus, the Bayesian inference combines two kinds of information: (i) the prior knowledge (belief, hypothesis) on the unknown parameters that may come from other data sets, logical intuition or the past experiences of the analyst and (ii) the information encapsulated in the observed data, which are represented by the likelihood function ${ }^{[26]}$.

A Bayesian inference is based on the application of the Bayes' theorem:

$$
P(P \mid D)=\frac{\mathrm{P}\left(\theta \mid D_{0} P_{1}\right)}{\mathrm{P}(\mathrm{D})}
$$

where $P(\theta)$ is the prior (marginal) distribution of the parameters $\theta$ (it does not take into account any information contained in the observed data $\mathrm{D}) ; \mathrm{P}(\theta \mid \mathrm{D})$ is the posterior distribution of the parameters $\theta$, having the data $\mathrm{D}$ observed; $\mathrm{P}(\mathrm{D} \mid \theta)$ is the conditional probability of the data, given the parameters $\theta$; and $P(D)$ is the prior (marginal) distribution of the data D.

$P$ (D) only serves as a normalization constant in order to obtain a unit area under the posterior PDF P $(\theta \mid D)$.

The conditional probability where the second argument is considered as a parameter is also called likelihood function: p $(\theta \mid D=d)$ or ${ }_{-}(D \mid \theta=\Theta)$. Bayes' theorem, using the aforementioned notation and having a continuous variable $\theta$ can be rewritten as follows:

$$
P(\theta \mid D)=\frac{\sin (\theta) P(\theta)}{D_{0}(D \mid \theta) P(\theta)}
$$

Where: integral in the denominator is computed through the entire parameter space $\Omega$.

The mathematical formulation of the way the hypothesis of the statistical properties of the parameters $\theta$ (the existing/prior beliefs) is updated by having observed the data $\mathrm{D}$ (in the light of new pieces of knowledge). Naturally, the final posterior distribution may serve as a prior distribution in a further Bayesian inference.

One of the main advantages of the Bayesian inference is that it results in a full posterior probability of the parameters: one may easily derive the credible intervals (counterparts of the traditional confidence intervals) of the parameters or any of their functions. Compared to this, the traditional methods of statistical analysis that are usually based on asymptotical assumptions, look at the parameters of a distribution function as fixed (unknown) constants, and the result of a statistical analysis is usually a point estimate of the parameters ${ }^{[24]}$. 
TABLE I.

THE HYDROLOGICAL AND GEOGRAPHICALCHARACTERISTIC OF THE RAINFALL SITES SELECTED IN SUDAN

\begin{tabular}{|c|c|c|c|c|c|c|c|c|c|c|}
\hline Site name & Code & $\begin{array}{c}\text { Data } \\
\text { length }\end{array}$ & Mean ARF & L-cv & L-skew. & L-kurt. & lat. & Long. & Area. & Elev. \\
\hline Abu Hamad & 02ABH640 & 58 & 10.6034 & 0.7029 & 0.5437 & 0.3206 & 19.533 & 33.333 & 122.1 & 299.6 \\
\hline Atbra & 02ATB680 & 58 & 59.3793 & 0.4231 & 0.1992 & 0.1345 & 17.667 & 33.967 & 30.4 & 316.3 \\
\hline Port Sudan & 03PSD641 & 15 & 63.8933 & 0.42 & 0.0645 & 0.0767 & 19.583 & 37.217 & 218.8 & 525.3 \\
\hline Khartuom & 04KHA721 & 102 & 150.8023 & 0.2835 & 0.1752 & 0.168 & 15.6 & 32.55 & 22.1 & 39.5 \\
\hline Gadarif & 05GDF752 & 41 & 603.5854 & 0.1053 & -0.0233 & 0.205 & 14.033 & 35.4 & 75.2 & 363.5 \\
\hline Kasala & 05KSL730 & 28 & 240.7354 & 0.198 & -0.023 & 0.1379 & 15.467 & 36.4 & 36.7 & 522.6 \\
\hline Madani & 06WMD751 & 58 & 305.9828 & 0.1762 & 0.0403 & 0.096 & 14.383 & 33.483 & 27.5 & 416.7 \\
\hline Elobiet & 08OBT771 & 90 & 359.3592 & 0.171 & 0.086 & 0.1399 & 13.183 & 30.217 & 185.3 & 492.8 \\
\hline Elfashir & 09FSH760 & 84 & 262.332 & 0.2223 & 0.193 & 0.1969 & 13.617 & 25.333 & 296.4 & 405.7 \\
\hline Elgeniena & 09GEN770 & 30 & 447.322 & 0.1901 & 0.0509 & 0.1614 & 13.483 & 22.45 & 79.4 & 526.2 \\
\hline Nyala & 10NYL790 & 43 & 393.3309 & 0.1376 & 0.0674 & 0.1113 & 12.05 & 24.883 & 127.3 & 775.8 \\
\hline Senar & 12SNR762 & 60 & 458.7983 & 0.1173 & -0.0342 & 0.1466 & 13.55 & 33.617 & 37.8 & 692 \\
\hline Malakal & 13MLK840 & 58 & 742.5498 & 0.1068 & 0.0463 & 0.1436 & 9.55 & 31.65 & 77.7 & 392.4 \\
\hline Waw & 14AWE852 & 28 & 1078.941 & 0.1003 & 0.042 & 0.0979 & 8.767 & 27.4 & 93.9 & 487.8 \\
\hline Juba & 15JUB941 & 43 & 961.4919 & 0.1105 & 0.0177 & 0.1987 & 4.867 & 31.6 & 22.9 & 468.2 \\
\hline
\end{tabular}

In general, an analytical computation of the integral in the denominator of (2) is very hard if not impossible; thus, that is the main reason why statistical methods based on the Bayesian inference have not been used frequently in the past ${ }^{[22]}$. The rapid development of computers in the past $2-3$ decades, however, has opened wide perspectives for numerical evaluation of complex mathematical problems. Markov chain Monte Carlo (MCMC) methods represent a class of such algorithms. By means of Monte Carlo simulations, the Metropolis-Hastings algorithm generates a Markov chain, which results in a sample, distribution of which converges to the posterior distribution $P(\theta \mid D)$. In other words, MCMC simulation draws samples from the posterior distribution of the parameters without having computed the normalization constant of (2) analytically ${ }^{[22]}$. The quality of the sample improves as a function of the number of steps of the Markov chain. The resulting data sample then serves for the estimation of marginal distributions of the joint probability distribution function, mean values, standard deviations, and confidence intervals not only for the parameters themselves but also for their arbitrary functions such as the required quantiles (design values) of the analyzed hydrological extremes ${ }^{[22]}$.

\section{Plotting Position Formulae}

There are several plotting position formulae (PPF) that are used in frequency analysis to get a quick glance on the empirical distribution of the data sample analyzed: to check whether they follow a particular distribution, if there are some errors or outliers etc. ${ }^{[22]}$.

One of the most frequently used PPFs is the one of Cunnane:
Where $\mathrm{n}$ denotes the sample size, $\mathrm{i}$ : is the rank of the observations in an ascending order, and pi is the cumulative probability of non-exceedance of the ith data.

In the case of a joint frequency analysis of systematic and historical data, the PPF (3) should be slightly modified according to the number of the historical events $\mathrm{k}$ that occurred during the whole n-year period analyzed. For the historical events, one should apply

$$
p_{j}=\frac{k_{1}-0.4}{n k+0.2}, 1=1, \ldots, k
$$

and for the systematic data

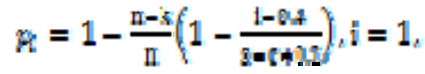

where the notation is in accordance with the one introduced in section 3.2 as well as with the formulae presented by Bayliss and Reed (2001, p. 34). In this section, we apply (4) and (5) for the visualization of the observed rainfall data on the probability plots.

\section{Probability Distribution Function}

To demonstrate different aspects of joint probability modeling of the systematic and the historical data, we employ the 3-parameter log-normal distribution (LN3). The selected distribution function is one of the most frequently used statistical models in flood frequency analyses ${ }^{[13]}$.

The cumulative distribution function of the LN3 distribution is

$$
\mathrm{F}(\mathrm{x})=\Phi(\mathrm{y})
$$

Where $\Phi$ is the CDF of the standard normal distribution and 


$$
y=\left\{\begin{array}{l}
-k^{-1} \log [1-k(x-\xi) \\
(x-\xi) / \alpha
\end{array}\right.
$$

Where $\xi, \alpha$, and $\mathrm{k}$ are the location, scale and shape parameters, respectively ${ }^{[13]}$. The special case with $\mathrm{k}=0$ yields the standard normal distribution.

\section{E. Setting of the Frequency Model}

A number of parameters to characterize various features of a hypothetical data set consisting both of systematic measurements and historical data are introduced. Herein, this notation on the records of rainfall from the 15 selected stations in Sudan is applied as follows:

- The length of the systematic observations is unequivocally given: $\mathrm{s}=53$ years.

- The 1962 rainfall event is exceptional in the light of the other rainfall peaks observed during the whole period with the systematic observations; thus, we consider this rainfall as historical one. Moreover, this is the only extraordinary event that appears in the analysis; therefore, $\mathrm{c}=1$.

- The perception threshold $X_{0}$ is unknown. Nevertheless, we suppose that $\mathrm{X}_{0}$ lies somewhere between the absolute maximum of the systematic records (1462 mm, recorded in 1962 (Wau station)) and the secondary maximum $(518 \mathrm{~mm}$, recorded in 1969 (Malakal station)). Since any information on rainfall having occurred before the systematic observations unknown, the value of the perception threshold level X0 just below the magnitude of the historical event, i.e., let $\mathrm{X}_{0}=600 \mathrm{~mm}$. Then a sensitivity analysis related to the choice of this value is performed.

- The length of the historical period $\mathrm{h}$ is also unknown. We only suppose that the extraordinary 1962 event has not been exceeded during the whole analyzed period $\mathrm{n}=\mathrm{h}+\mathrm{s}$. In other words, we have to make an initial estimate of the return period of this extraordinary event, and assume that the magnitudes of all the unknown events that have occurred in the 'historical' period do not exceed the perception threshold $\mathrm{X}_{0}$ (i.e., $\mathrm{m}=0$ ). A sensitivity analysis regarding the choice of $h$ is also carried out in this section.

- Since the magnitude of the historical rainfall event is very well known, it is incorporated into the statistical model. Uncertainties in the magnitude of this event are not considered in the analysis herein.

- The Bayesian approach allows for choosing any prior distribution $\mathrm{p}(\theta)$ of the parameters $\theta$ of the selected distribution function (2). Since an arbitrary choice is allowed, we choose the simplest solution: we do not put any stress on the priors of $\theta$, i.e., we use uniform initial distribution $\mathrm{p}(\theta)=$ const., which does not have effects on the evaluation of (2).

\section{F. Selection of the Length of Historical Period}

The way the choice of the length of the historical period $h$ affects the quantile estimates of rainfall frequency analysis of systematic and historical rain events is presented in Fig. 3 and Table II. The panel of Fig. 1 consists of 6 subplots. From the top left corner the first plot displays the case with the historical event excluded ('No historical information' in its title), i.e., a frequency analysis only based on the records from the period 1902-2000. The other plots are related to a joint analysis of systematic and historical information with different estimates of the parameter $h$, namely $h=500,1000$, 1500,2000 and 3000 years. The solid line in the middle of the plots is the fitted distribution function, while the dashed line above (below) it is the upper (lower) bound of the 5$95 \%$ confidence intervals of rain quantiles. The systematic data are represented by empty circles, while the historical information is depicted by a solid black circle. The perception threshold has been set to $X_{0}=600 \mathrm{~mm}$ in all simulations related to Fig. 1.
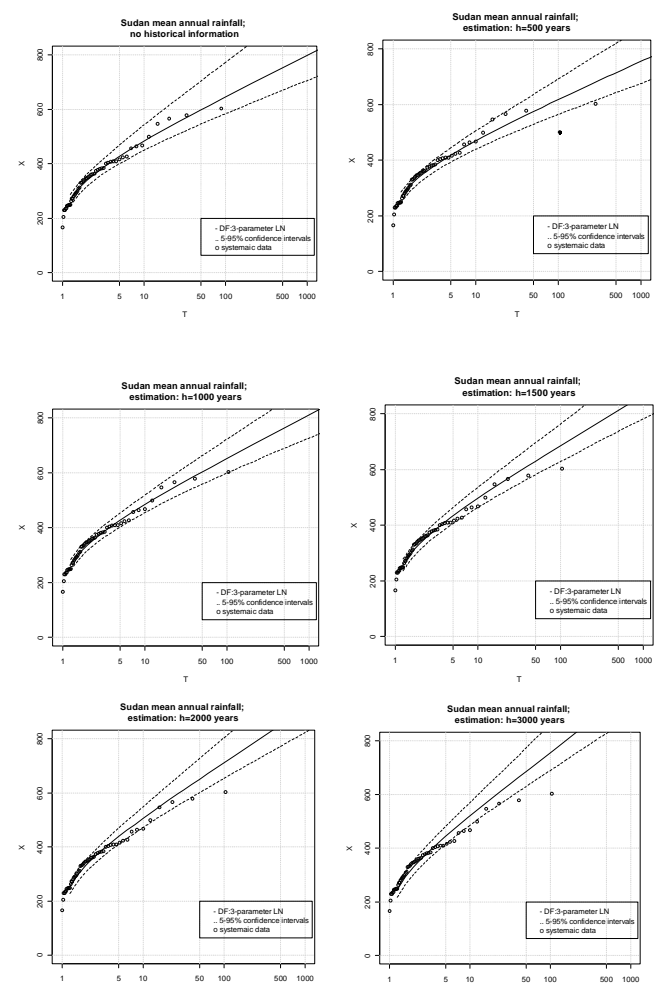

Figure 1. Three-parameter log-normal distribution function (LN3) fitted to the Sudan mean annual rainfall stations: sensitivity analysis related to the selection of the length of the historical period h. DF stands for distribution function. 


\begin{tabular}{|c|c|c|c|c|c|c|}
\hline & \multicolumn{2}{|c|}{ TABLE II. } & \multicolumn{4}{|c|}{ ESTIMATION OF THE RAIN QUANTILES QT } \\
\hline $\begin{array}{c}\text { Return period T } \\
\text { (years) }\end{array}$ & MCMC settings & QT (mm) & $\mathrm{CI}_{0.05}(\mathrm{~mm})$ & $\mathrm{CI}_{0.95}(\mathrm{~mm})$ & $\Delta \mathrm{CI}(\mathrm{mm})$ & $\Delta \mathrm{CI} / \mathrm{QT}(\%)$ \\
\hline \multirow[t]{6}{*}{100} & no hist. information & 482.99 & 448.91 & 542.56 & 93.64 & 19.388 \\
\hline & $\mathrm{h}=500$ years & 469.45 & 438.40 & 505.28 & 66.87 & 14.246 \\
\hline & $\mathrm{h}=1000$ years & 484.13 & 454.91 & 519.17 & 64.26 & 13.27 \\
\hline & $\mathrm{h}=1500$ years & 496.44 & 463.10 & 536.31 & 73.21 & 14.74 \\
\hline & $\mathrm{h}=2000$ years & 505.94 & 472.49 & 548.05 & 75.55 & 14.93 \\
\hline & $\mathrm{h}=3000$ years & 520.31 & 485.79 & 570.16 & 84.36 & 16.21 \\
\hline \multirow[t]{6}{*}{1000} & no hist. information & 645.55 & 583.76 & 772.64 & 188.88 & 29.25 \\
\hline & $\mathrm{h}=500$ years & 618.13 & 564.45 & 693.08 & 128.62 & 20.80 \\
\hline & $\mathrm{h}=1000$ years & 652.14 & 599.27 & 722.48 & 123.21 & 18.89 \\
\hline & $\mathrm{h}=1500$ years & 685.13 & 628.70 & 762.80 & 134.10 & 19.57 \\
\hline & $\mathrm{h}=2000$ years & 711.27 & 654.10 & 803.93 & 149.83 & 21.06 \\
\hline & $\mathrm{h}=3000$ years & 755.53 & 689.69 & 864.69 & 175.00 & 23.16 \\
\hline \multirow[t]{6}{*}{10000} & no hist. information & 950.34 & 824.44 & 1250.24 & 425.80 & 44.80 \\
\hline & $\mathrm{h}=500$ years & 891.97 & 783.22 & 1062.01 & 278.78 & 31.25 \\
\hline & $\mathrm{h}=1000$ years & 970.05 & 852.67 & 1129.44 & 276.77 & 28.53 \\
\hline & $\mathrm{h}=1500$ years & 1052.6 & 932.29 & 1238.83 & 306.53 & 29.12 \\
\hline & $\mathrm{h}=2000$ years & 1120.01 & 994.49 & 1356.44 & 361.95 & 32.31 \\
\hline & $\mathrm{h}=3000$ years & 1242.13 & 1089.66 & 1528.98 & 439.32 & 35.36 \\
\hline
\end{tabular}

Table II. shows the estimation of the rain quantiles QT and their confidence intervals corresponding to the return periods $\mathrm{T}=100,1000$ and 10000 years at the Sudan statio, with no historical information involved, and various assumptions concerning the length of the historical period $\mathrm{h}$, respectively. $\mathrm{CI}_{0.05}\left(\mathrm{CI}_{0.95}\right)$ is the $5 \%(95 \%)$ confidence limit of the estimates QT, $\Delta \mathrm{CI}=\mathrm{CI}_{0.95}-\mathrm{CI}_{0.05}$

\section{G. Selection of Perception Threshold}

According to the magnitude of the historical plod peak $(1462.9 \mathrm{~mm})$ and the maximum of the rest of the rain peak records is $(518 \mathrm{~mm})$, we selected 6 different values for the sensitivity analysis related to the threshold $\mathrm{X}_{0}$ :

- $1200 \mathrm{~mm}$,

- $1000 \mathrm{~mm}$,

- $600 \mathrm{~mm}$,

- $580 \mathrm{~mm}$,

- $520 \mathrm{~mm}$,

- $520 \mathrm{~mm}$

On the other hand, the length of the historical period is set to a constant value, $h=1000$ years. The graphical outputs of the analysis are presented through a panel of plots in Fig. 2 where the different threshold values are accentuated by a corresponding horizontal line. The characteristics of the selected quantiles and their CIs are summarized in Table III.

Table III shows the estimation of the rain quantiles QT and their confidence intervals corresponding to the return periods $\mathrm{T}=100,1000$ and 10000 years at the Sudan rain stations, with various assumptions concerning the perception threshold $\mathrm{X}_{0} . \mathrm{CI}_{0.05}\left(\mathrm{CI}_{0.95}\right)$ is the 5\% (95\%) confidence limit of the estimates QT, $\Delta \mathrm{CI}=\mathrm{CI}_{0.95}-\mathrm{CI}_{0.05}$
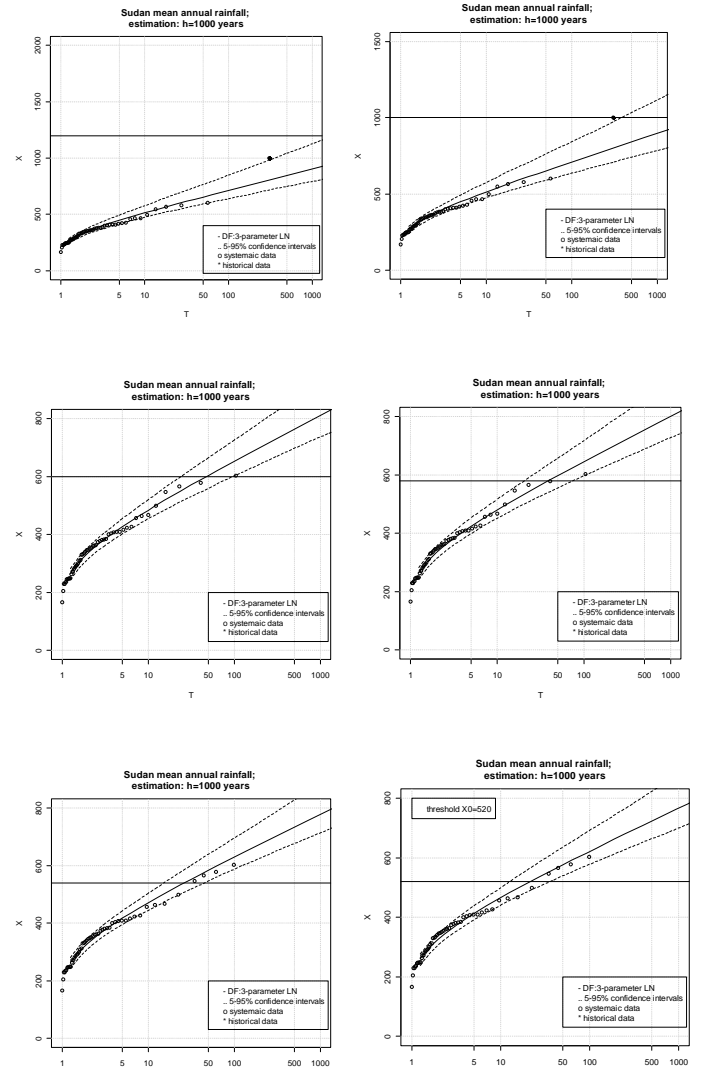

Figure 2. Three-parameter log-normal distribution function (LN3) fitted to the Sudan mean annual rain stations: sensitivity analysis related to the selection of the perception threshold $\mathrm{X}_{0}$. DF stands for distribution function.

TABLE III.

ESTIMATION OF THE RAIN QUANTILES QT

\begin{tabular}{|c|c|c|c|c|c|c|}
\hline $\begin{array}{l}\text { Return period } \\
\text { (years) }\end{array}$ & MCMC settings & QT (mm) & $\mathrm{CI} \mathrm{I}_{0.05}(\mathrm{~mm})$ & $\mathrm{CI}{ }_{0.95}(\mathrm{~mm})$ & $\Delta \mathrm{CI}(\mathrm{mm})$ & $\Delta \mathrm{CI} / \mathrm{QT}(\%)$ \\
\hline \multirow[t]{3}{*}{100} & $\mathrm{X} 0=1200 \mathrm{~mm}$ & 711.40 & 639.31 & 847.97 & 208.66 & 29.339 \\
\hline & $\mathrm{X} 0=1000 \mathrm{~mm}$ & 709.04 & 636.30 & 841.87 & 205.57 & 28.99 \\
\hline & $\mathrm{X} 0=600 \mathrm{~mm}$ & 652.57 & 602.26 & 726.26 & 123.99 & 19.00 \\
\hline
\end{tabular}




\begin{tabular}{|l|l|l|l|l|l|l|}
\hline \multirow{5}{*}{} & $\mathrm{X} 0=580 \mathrm{~mm}$ & 645.25 & 597.23 & 718.56 & 121.32 & 18.80 \\
\cline { 2 - 7 } & $\mathrm{X} 0=540 \mathrm{~mm}$ & 629.71 & 587.40 & 696.50 & 109.10 & 17.32 \\
\cline { 2 - 7 } & $\mathrm{X} 0=520 \mathrm{~mm}$ & 621.61 & 577.97 & 692.24 & 114.26 & 18.38 \\
\hline \multirow{5}{*}{1000} & $\mathrm{X} 0=1200 \mathrm{~mm}$ & 902.71 & 792.42 & 1126.34 & 333.92 & 36.99 \\
\cline { 2 - 7 } & $\mathrm{X} 0=1000 \mathrm{~mm}$ & 898.58 & 785.13 & 1116.99 & 331.86 & 36.93 \\
\cline { 2 - 7 } & $\mathrm{X} 0=600 \mathrm{~mm}$ & 811.96 & 737.53 & 930.03 & 192.49 & 23.70 \\
\cline { 2 - 7 } & $\mathrm{X} 0=580 \mathrm{~mm}$ & 801.32 & 728.64 & 921.22 & 192.58 & 24.03 \\
\cline { 2 - 8 } & $\mathrm{X} 0=540 \mathrm{~mm}$ & 778.55 & 714.58 & 884.84 & 170.25 & 21.86 \\
\cline { 2 - 8 } & $\mathrm{X} 0=520 \mathrm{~mm}$ & 767.28 & 699.87 & 880.52 & 180.65 & 23.54 \\
& $\mathrm{X} 0=1200 \mathrm{~mm}$ & 1098.22 & 943.08 & 1429.42 & 486.34 & 44.28 \\
\cline { 2 - 8 } & $\mathrm{X} 0=1000 \mathrm{~mm}$ & 1092.06 & 932.02 & 1409.75 & 477.72 & 43.74 \\
\cline { 2 - 8 } & $\mathrm{X} 0=600 \mathrm{~mm}$ & 971.98 & 868.36 & 1141.60 & 273.24 & 28.11 \\
\cline { 2 - 8 } & $\mathrm{X} 0=580 \mathrm{~mm}$ & 957.74 & 855.94 & 1131.31 & 275.37 & 28.75 \\
\cline { 2 - 8 } & $\mathrm{X} 0=540 \mathrm{~mm}$ & 927.12 & 839.84 & 1075.52 & 235.68 & 25.42 \\
\cline { 2 - 8 } & $\mathrm{X} 0=520 \mathrm{~mm}$ & 912.47 & 821.27 & 1077.80 & 256.52 & 28.11 \\
\hline
\end{tabular}

\section{H. The Effect of the Record Length on the Result}

In the report by Szolgay et al. (2008), the collective of authors raised concerns about the appropriateness of the flood peak measurements made in the last decades of the 19th century (possible inhomogeneities present in the data series; details not reported herein). Due to this fact we decided to exclude the problematic part of the data series and restrict the analysis to the supposedly homogeneous data set belonging to the period 1900-2002.In this section the analysis is restricted to the data set belonging to the period 1900-2002. The results of this analysis are presented in Fig. 3 and Table IV.
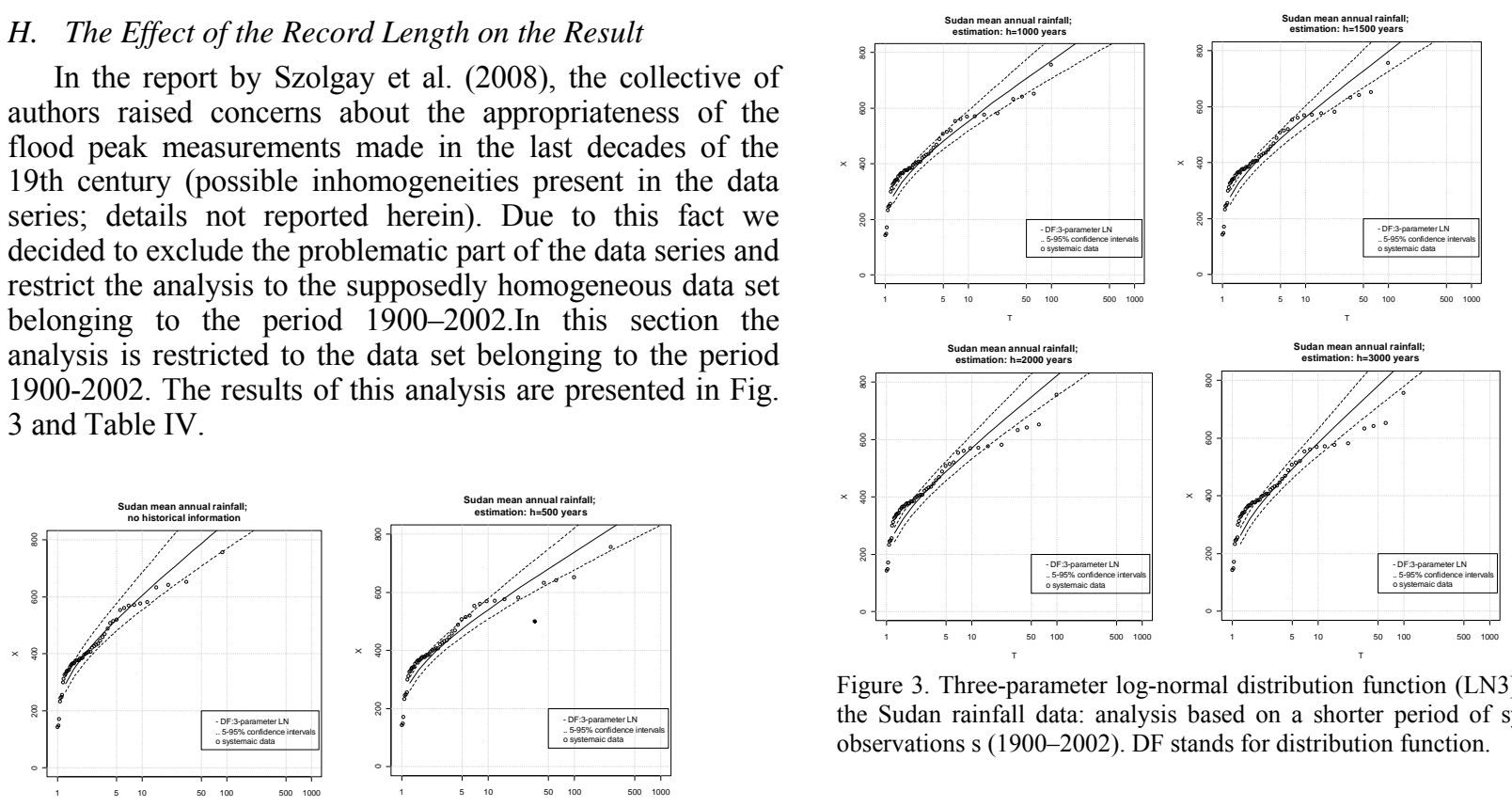

Figure 3. Three-parameter log-normal distribution function (LN3) fitted to the Sudan rainfall data: analysis based on a shorter period of systematic observations s (1900-2002). DF stands for distribution function.

TABLE IV.

ESTIMATION OF THE RAIN QUANTILES QT

\begin{tabular}{|c|c|c|c|c|c|c|}
\hline $\begin{array}{c}\text { Return period } \mathbf{T} \\
\text { (years) }\end{array}$ & MCMC settings & QT (mm) & $\mathrm{CI}_{0.05}(\mathrm{~mm})$ & $\mathrm{CI}_{0.95}(\mathrm{~mm})$ & $\Delta \mathrm{CI}(\mathrm{mm})$ & $\Delta \mathrm{CI} / \mathrm{QT}(\%)$ \\
\hline \multirow[t]{6}{*}{100} & no hist. information & 863.31 & 769.24 & 1039.86 & 270.62 & 31.34 \\
\hline & $\mathrm{h}=500$ years & 738.98 & 677.18 & 821.11 & 143.93 & 19.47 \\
\hline & $\mathrm{h}=1000$ years & 770.22 & 707.14 & 854.86 & 147.71 & 19.17 \\
\hline & $\mathrm{h}=1500$ years & 797.71 & 727.13 & 890.14 & 163.00 & 20.43 \\
\hline & $\mathrm{h}=2000$ years & 823.01 & 752.78 & 919.65 & 166.86 & 20.27 \\
\hline & $\mathrm{h}=3000$ years & 865.61 & 780.06 & 980.26 & 200.20 & 23.12 \\
\hline \multirow[t]{6}{*}{1000} & no hist. information & 1120.81 & 972.48 & 1416.38 & 443.90 & 39.60 \\
\hline & $\mathrm{h}=500$ years & 929.21 & 831.91 & 1067.87 & 235.96 & 25.39 \\
\hline & $\mathrm{h}=1000$ years & 981.66 & 877.31 & 1129.69 & 252.37 & 25.70 \\
\hline & $\mathrm{h}=1500$ years & 1030.10 & 917.61 & 1194.06 & 276.45 & 26.83 \\
\hline & $\mathrm{h}=2000$ years & 1076.13 & 961.98 & 1244.15 & 282.16 & 26.22 \\
\hline & $\mathrm{h}=3000$ years & 1156.56 & 1016.18 & 1360.73 & 344.54 & 29.79 \\
\hline \multirow[t]{6}{*}{10000} & no hist. information & 1389.48 & 1178.53 & 1830.11 & 651.58 & 46.89 \\
\hline & $\mathrm{h}=500$ years & 1122.01 & 984.82 & 1327.40 & 342.58 & 30.53 \\
\hline & $\mathrm{h}=1000$ years & 1198.61 & 1049.46 & 1421.61 & 372.14 & 31.04 \\
\hline & $\mathrm{h}=1500$ years & 1271.38 & 1105.49 & 1520.33 & 414.83 & 32.62 \\
\hline & $\mathrm{h}=2000$ years & 1341.92 & 1177.18 & 1599.29 & 422.10 & 31.45 \\
\hline & $\mathrm{h}=3000$ years & 1468.1 & 1258.12 & 1791.22 & 533.10 & 36.31 \\
\hline
\end{tabular}

Table IV shows the estimation of the rain quantiles QT and their confidence intervals corresponding to the return 
periods $T=100,1000$ and 10000 years at the Sudan rainfall stations, based on a shorter period of systematic observations $\mathrm{s}(1900-2002)$. CI0.05 (CI0.95) is the 5\% (95\%) confidence limit of the estimates QT, $\Delta \mathrm{CI}=\mathrm{CI}_{0.95}-\mathrm{CI}_{0.05}$

\section{DISSCUSION OF MCMC RESULTS}

The main results of the frequency analysis are presented in terms of figures (probability plots) and tables, where the main focus was set to the rainfall quantiles corresponding to return periods $\mathrm{T}=100,1000$ and 10000 years. The latter value, although it may seem unreasonably high, is justified by the fact that the rainfall quantile corresponding to the return period of $\mathrm{T}=10000$ years has been defined as the critical design value.

The sensitivity analyses is presented, which examine the effects of the choice of the most important parameters of the statistical model (the length of the historical period $h$, the threshold $\mathrm{X}_{0}$ and the length of the systematic records $\mathrm{s}$ ) on the quantile estimates and the width of their confidence intervals.

In Fig. 3 comparing the first subplot with no historical information included and the rest of the plots corresponding to different $h$ values it is discernible that the inclusion of the historical event with an extraordinary magnitude reduces the width of the confidence bounds. This fact is underpinned by the numerical evaluation of the confidence intervals (CIs) of the representative rain quantiles: both the absolute and relative widths of the $\mathrm{CI}$ ( $\Delta \mathrm{CI}$ and $\Delta \mathrm{CI} / \mathrm{QT}$, respectively) for the near highest value of the parameter $h$ are approximately half of the widths of the corresponding CI for the alternative with no historical information involved (Table II). This holds for all three return periods considered. From Figures 3 it is also clear that the value of $h$ controls the slope of the fitted CDF: higher values of $h$ are associated with less steeper CDFs.

The inclusion of historical information evidently reduces the uncertainty in the quantile estimates. Nevertheless, one of the most important questions still remains open: which of the selected $h$ values should be preferred? In a traditional rain frequency analysis that is only based on systematic data, different goodness-of-fit tests (such as the test of $\chi 2$, test of Kolmogorov and Smirnov or the Z-test; see, e.g., Wilks, ${ }^{[13]}$ ) can be applied in a simple way to assess the 'closeness' of the fitted distribution to the observed data. Nevertheless, as soon as any historical information is incorporated, testing the goodness of the fit becomes a difficult business. As far as known, there are no methods in the literature to accomplish such a task. Therefore, decide is made to use a visual inspection method. We check whether $90 \%$ of the observed data visualized through the modified plotting position formulae lie or do not lie within the $90 \%$ confidence interval estimated by the MCMC simulation procedure. Although the method is subjective, it can indicate with respect to the CDF where the fit is not sufficiently good, the presence of changes of slopes (e.g., due to threshold effects) or whether another type of distribution would be more suitable. For these reasons, as for other visual techniques, our visual inspection method could be used in the engineering practice. Based on the visual inspection, we eliminated the two highest estimates of $\mathrm{h}$ (2000 and 3000 years; see two bottom plots in Fig. 3 since in these two cases, a larger number of data points (which belong to the highest rainfall peaks observed during the period with systematic records, and therefore, are of enhanced importance) get outside the confidence bounds. In order to find the only acceptable $\mathrm{h}$ value, we also fitted another distribution functions (e.g., generalized extreme value, 3-parameter log-Pearson, 2-parameter lognormal etc.) to the same data set with the same settings of the statistical model. The results are not reported herein; however, taking into consideration the visual check of other distribution functions we conclude that the most acceptable estimate of the length of the historical period is about $h=1000-1500$ years.

From Fig. 2 and table III the outcomes indicate that the gradual lowering of the perception level results in two effects: a) narrower uncertainty bounds (by setting the threshold $X_{0}$ lower and lower), and b) less steep slope of the fitted distribution function. Both effects can easily be explained.

Case a) means that by setting the threshold $\mathrm{X}_{0}$ lower and lower, one assumes that the unknown past values were not particularly high, i.e., they varied in a narrower range. At the same time, case b) means that having a lower threshold $\mathrm{X}_{0}$, the magnitudes of the unknown peak discharges that have occurred in the past are supposed to be lower, therefore, the distribution function is also fitted towards the lower values. While the first effect could, in principle, be beneficial for the quantile estimates by having narrower CIs, this theoretical advantage is outweighed by the second effect, which similarly to the one discussed above - puts several data points outside the confidence bounds. Based on these considerations we conclude that the initial selection of the perception threshold $\left(\mathrm{X}_{0}=600 \mathrm{~mm}\right)$ is acceptable for the recent analysis. It also can be higher; however, it definitely should not be set considerably lower.

Keeping the settings of the statistical model applied so far, and having a shorter period of systematic observations, the MCMC simulations lead to lower quantile estimates compared to the results based on the whole data records ( Table II). It is likely that this is only a sampling effect since the eliminated period 1950-1996 contains a number of rainfall events of a relatively high magnitude. On the other hand, the effect of the shorter period s on the uncertainty of the estimated quantiles is unclear (Table IV). Lower quantile estimates QT are accompanied with narrower absolute width of the confidence intervals $\Delta \mathrm{CI}$; however, these effects result in enhanced relative width of the CIs $\Delta$ CI/QT (cf. Table IV and Table II).

At the present stage of the analysis it is evident that the two parameters $\mathrm{h}$ and $\mathrm{X}_{0}$ are the most dominant controls of the width of the CIs. In order to derive further information on the role of $\mathrm{s}$ in the statistical model, a deeper analysis is needed (possibly accompanied by further Monte Carlo simulations), and such a task is beyond the scope of the recent study. 


\section{CONCLUSION AND FINAL EVALUATION}

As the particular results of the case study indicate, among the number of parameters of the statistical model to be chosen, the length of the historical period $h$ and the perception threshold $\mathrm{X}_{0}$ have the most remarkable influence on the width of the confidence intervals of the estimated rain quantiles. The higher the assumption of $\mathrm{h}$ (i.e., analysis reaches further back to the past) and/or the lower the assumption of $\mathrm{X}_{0}$ (i.e., the unknown mean annual rains from the past are assumed to be generally low), the narrower are the confidence bounds of the estimated quantiles. Nevertheless, selecting high values of $h$ and/or low values of $\mathrm{X}_{0}$ for the model yields a great risk that the analyst may be wrong of not considering all the (unknown) extreme events that might have occurred during the period of length $h$ in the past. It is therefore advised to be rather prudent in selecting the model parameters to have confidence intervals only moderately narrower compared to the alternative with no historical information, instead of having considerably narrower confidence intervals but making wrong inference on "unknown" historical data that are not well estimated.

A particularly satisfying result of this study was that the outcomes of the method are relatively robust when considering the uncertainties in the estimated historical rainfall and the subjective choices in the parameterizations of the method.

\section{REFERENCES}

[1] Acreman, M. C. \& Wiltshire, S. E. (1987). Identification of regions for regional flood frequency analysis. EOS, 68(44), 1262, an abstract.

[2] Alcoverro, J., Corominas, J., Gomez, M., 1999. The Barranco de Aras flood of 7 August 1996 (Biescas, Central Pyrenees, Spain). Engineering Geology 51 (4), 237-255.

[3] Beable, M. E. and McKerchar, A. I. (1982). "Regional flood estimation in New Zealand", Water and Soil Technical Publication 20 , Ministry of Works and Development, Wellington, N. Z.

[4] Bobee, B. \& Robilalle, R. (1977). Correction and bias estimation of the coefficient of skewness. Water Resources Research, 11(6), 851854.

[5] Burn, D. H. (1990). Evaluation of regional flood frequency analysis with a region of influence approach. Water Resources Research, 26(10), 2257-2265.

[6] Castellarin, A., 2007. Probabilistic envelope curves for design flood estimation at ungauged sites. Water Resources Research 43, W04406. doi: 10.1029/2005WR004384.

[7] Costa, J.E., 1987. A comparison of the largest rainfall-runoff floods in the United States with those of the People's Republic of China and the world. Journal of Hydrology 69, 101-115.

[8] Costa, J.E., Jarrett, R.D., 2008. An evaluation of selected extraordinary floods in the United States reported by the U.S. geological survey and implications for future advancement of flood science. Scientific investigations report 2008-5164, US Geological Survey, Reston, Virginia, USA.

[9] Cunnane, C. (1978). "Unbiased plotting positions - A review", Journal of Hydrology, Vol. 37, No. 3/4, pp. 205-222.

[10] Dalrymple, T. (1960). Flood frequency methods, U.S. Geological Survey. Water supply paper 1543A, 11-51.

[11] Gaume, E., 2006. On the asymptotic behavior of flood peak distributions. Hydrology and Earth System Sciences 10 (2), 233-243.

[12] Hosking, J.R. \& Wallis J.R. (1986 a). The value of historical data in flood frequency analysis. Water Resources Research, 22(1), 16061612 .
[13] Hosking, J.R.M. and Wallis, J.R. (1997). Regional Frequency Analysis: An Approach based on L-Moments. Cambridge University Press, Cambridge, UK.

[14] Institute of Hydrology. (1999). Flood estimation handbook, Institute of Hydrology, Wallingford, UK.

[15] Kuczera, G. (1982a). "Combining Site-Specific and Regional Information: An Emprical Bayes Approach",Water Resources Research, Vol. 18, No. 2, pp. 306-314.

[16] Leese, M. N. (1973a). The use of censored data in estimating T-year floods. Proceedings of the UNESCO/WMO/IAHS Symposium on the Design of Water Resources Projects with inadequate data, Madrid, Vol. 1, 235-247.

[17] Merz, R., Bloschl, G., 2003. A process typology of regional floods. Water Resources Research 39 (12), $1340 . \quad$ doi: 10.1029/2002WR001952.

[18] Mimikou, M., 1984. Envelope curves for extreme flood events in north-western and western Greece. Journal of Hydrology 67, 55-66.

[19] Natural Environment Research Council. (1975). "Flood Studies Report”, Vol. 1. Natural Environment Research Council, London.

[20] Ouarda, T. B. M. J., M. Lang, B. Bobee, J. Bernier, and P. Bois. 1999. Analysis of regional flood models utilized in France and Quebec. Revue des Sciences de l'Eau 12:155-182.

[21] Parent, E., and J. Bernier. 2003. Encoding prior expert's judgments to improve risk analysis of extreme hydrological events via POT modeling. Journal of Hydrology 283:1-18.

[22] Reis, D. S., and J. R. Stedinger. 2005. Bayesian MCMC flood frequency analysis with historical information. Journal of Hydrology 313:97-116.

[23] Roberts, G. O., and W. R. Gilks. 1994. Convergence of Adaptive Direction Sampling. Journal of Multivariate Analysis 49:287-298.

[24] Rodier, J.A., Roche, M., 1984. World Catalogue of Maximum Observed Floods. IASH Publication 143, IASH Press.

[25] Solin, L., 2008. Analysis of floods occurrence in Slovakia in the period 1996-2006. Journal of Hydrology and Hydromechanics 56 (2), 95-107 (in Slovak).

[26] Stedinger, J. R. \& Cohn, T. A. (1986). Flood frequency analysis with historical and paleoflood information. Water Resources Research, 22(5), 785-793.

[27] Svoboda, A., Pekarova, P., 1998. The catastrophic flood of July 1998 in the Mala Svinka catchment - its simulation. Journal of Hydrology and Hydromechanics 46 (6), 356-365 (in Slovak).

[28] UNESCO, 1976. World Catalogue of Very Large Floods. The UNESCO Press. 424pp

[29] Wiltshire, S. E. (1986a). "Regional flood frequency analysis I: Homogeneity statistics", Hydrological Sciences Journal, Vol. 31, pp. 321-333. 